\title{
The Macroeconomic Effects of Information Asymmetry in the Capital Markets
}

\author{
Robert G. KUKLIK
}

\section{Introduction}

The objective of this article is an attempt to describe possible effects of the phenomenon called "information asymmetry" in the activity of capital markets, on the general macroeconomic equilibrium. As it is generally known, the capital market dynamics can exist at various levels of the so called "market efficiency", in other words at varying volume and quality of information penetrating the prices of the traded securities. When various segments of the capital market are not evenly and/or sufficiently informed, then investment decisions can be asymmetrically affected in terms of the risk-return criterion perception. Different degrees of such a situation can be described and more or less tested by the well known framework consisting of the "weak, semi-strong and strong form" market efficiency tests. The notion of market efficiency simply states that the market price of a security represents the market's consensus estimate of the value of that security. Those investors who choose to hold the security must think that it is worth more than the current market price while those who do not must think that it is worth less. According to the efficient market hypothesis (EMH) an efficient financial market is supposed to exist when the security prices reflect all available public information about the economy, financial markets as well as the specified company involved. The implication is that market prices of individual securities adjust very rapidly to the new information. As a result, security prices are said to fluctuate randomly about their "intrinsic" values. Any new information can result in a change in this intrinsic value of a security, but subsequent security price movements are said to be following the process known as a "random walk" which assumes that successive returns are uncorrelated, i. e. serially independent and that the returns are identically distributed over the span of time. This requirement is of course

Robert G. Kuklik, MBA - Ph.D. student; Department of Banking and Insurance, Faculty of Finance and Accounting, University of Economics, Prague, W. Churchill Sq. 4, 13067 Prague 3, Czech Republic; <elf.rob@centrum.cz>. 
valid, "provided you assume the bell curve is relevant and that prices move continuously" (Mandelbrot \& Hudson, 2006, p.77). In this context it is perhaps understandable that markets of different profiles have also a different information asymmetry complexion depending on their turnovers, liquidity depth, etc. For example the Czech capital market shows that ... "the daily return of either index PX-50 or the independent titles . . . are not independent and therefore the stock prices do not behave as the random walk and therefore the Czech stock market does not behave efficiently" (Van Quang, 2007, p. 770).

There should be no doubt that declining information asymmetry causes an increase of the implicit market efficiency in the above sense. However, the "rational" investors cannot in fact only rely on the comforting message of the EMH that all you need to do to obtain an expected return is to take the appropriate level of commensurate risk. Without probably any dispute, this rule can apply to some groups of investors in certain large, developed and dynamic markets but seemingly as a matter of exception only. But on the other hand, it is necessary to point out that the investors' decision-making process also involves another number of different even behavioral factors including for example the emotional condition of market participants at different points in time and the current balance of advantage between competing groups of these participants, together with the constant emergence of the new profit-making opportunities. Because the economic systems also involve human interactions which almost by definitions are more complex than interactions of for example objects governed by fixed, known and simplified rigorous rules, the risk-return relationship therefore becomes rather unstable over time and the random walk hypothesis might therefore turn due to such pricing bias at certain instances less valid, to be therefore enlarged into a more general framework of the concept sometimes perhaps called "adaptive market hypothesis". A good example of the incidence of information asymmetry hampering the market effectiveness is corporate mergers, when .... "target stockholders earn relatively large positive abnormal returns around the time of merger proposal. These abnormal returns are a direct result of the merger proposal and do not reflect any pre-merger good performance by these firms" (Dodd, 1980, p. 134).

Consequently, although the phenomenon of market effectiveness directed by information asymmetry fundamentally applies, ceteris paribus, the classical risk/return parity appears to have a broader dimension enriched by the aforementioned factors. Nevertheless, although such factors influencing investors' decision making had not been 
explicitly considered, their acknowledgment does not exclude creation of an analysis postulating the causal effect of information asymmetry on the market returns and therefore affecting the macroeconomic variables. Further to that, generally information does not also have to be "complete", when as a matter of uncertainty it is not possible for a lack of it to determine probabilities of particular future market outcomes in a reliable way. However, even such information can be considered "symmetrical", so long as it is accessible by all market participants. The security prices imply the value of required returns as determined by specific "states of the world", i. e. the combinations of values outlining the space of particular investment opportunities. As long as then there exists the same number of independent "profit vectors" i.e. the firms as the states, the individual investors can explore a full set of possibilities of trading among the states and the market can therefore be considered "complete". Otherwise, such a market fails to secure supply of a particular commodity even though the demand is prepared to meet a price higher than its cost of production and therefore a number of acceptable investment alternatives is for the individual investors reduced thus:

... "shareholders will have different views on the best investment policy because their marginal valuations of income in different states have not been equalized by trading in a complete set of markets. Not only will shareholders have different discount factors, but the firms will not be able to infer them from observable stock market values and state contingent output." (Gravelle - Reeds, 1992, p. 732)

In this context there is another implication of the broaden view of the market behavior - the market efficiency based on development in the information asymmetry could go hand in hand with increasing market "completeness" in the form of emerging new profit opportunities which provides the continuing incentive for active investors to remain in the market. The capital markets can therefore be considered intrinsically "efficient" and "complete" when the prices of securities due course of reaching the higher level of information symmetry contain an increasing volume of information concerning investment and when such information is also complete in the above sense, i.e. covering the existing scope of investment opportunities to the maximum extend. This can therefore be envisaged as a situation when the profit allocation process hypothetically satisfies the so called Pareto optimum, i. e. the point where the marginal revenue of the next investment opportunity is equal for all market participants thus implying equality of the corresponding marginal opportunity costs. 


\section{Analysis}

On the basis of the supply-demand interaction process the market is offering a security at a certain price in the period $t$ which consists of the expected return component $\overline{R_{j t}}$ determined by the market itself i. e. $\overline{R_{m t}}$ and of a segment of the return reflecting the non-market, also called "unsystematic", time-stable and "expected" factor $\alpha$ as well as the random disturbance term $e_{j t}$, representing specific economic characteristics of a particular investment (e.g. of a firm). Using the assumption of macroeconomic influence of the information asymmetry, the model of the "pseudo-effective" capital market was developed, aiming to identify possible macroeconomic effects on the basis of a comparison of such a model with performance of the actual capital market. For this purpose a hypothetical portfolio risk/return "shadow" framework was defined with the aid of the Single Index Model (Market Model, SIM) where the exogenous components $\alpha$ and $e_{j t}$, i.e. the over-the-period of time constant, "expected" proportion of the unsystematic return and its random variable are determined as also the functions of the market movements $\beta$, thus $\overline{R_{j t}}$ $=\sigma_{j} / \sigma_{m} \overline{R_{m t}}$, i. e. where $r_{j m}=1$.

This construction is then compared with the actual market performance, using the basic parameters $\overline{R^{\prime}{ }_{j}} / \sigma^{\prime} j$, (the actual market) and $R_{j} / \sigma_{j}$ (the "shadow market") for $\sigma_{j}^{\prime}=\sigma_{j} r_{j m}$ with $\overline{R_{m}}, \sigma_{m}$, representing, the market return and its dispersion. Assuming the initial ex ante position of the return $\overline{R^{\prime}{ }_{j t 1}}$, to be lower than the implicit "efficient" rate $\overline{R_{j t}}$, then an increase of the market efficiency can cause a rise of the market return towards this hypothetical rate. Within the framework of the model, the increasing market efficiency is demonstrated by the rising value of the correlation coefficient $r_{j m}$ with the simultaneous decline of the size of components representing the "non-market return". This process is likely generated by an increase in the informational market throughput reflected in the prices of securities. This possibly occurs in combination with increasing market "completeness" in the form of emerging additional profit-making opportunities thus rising the overall market capitalization. The upward movement of the $\overline{R^{\prime}{ }_{j t 1}}$, towards the intrinsic efficient market equilibrium level also causes a rise in the volatility of the return's dispersion expressed by $\sigma_{j}^{\prime}$ commensurate with the increasing risk profile of the asset portfolio therefore reaching the mean/variance equilibrium 
Kuklik, R. G.: The Macroeconomic Effects of Information Asymmetry in the Capital Markets.

ratio $\overline{R_{j t}} / \sigma_{j}$. In the same way the actual asset's coefficient $\beta_{j}^{\prime}$ is also attaining its "efficiency equilibrium" level $\beta_{j}$ finally consistent with the coefficient $\beta_{m}$ when $\sigma_{j}$ is reaching $\sigma_{m}$ for a growing investment "pseudoefficient" portfolio (refer to Fig. 1). Consequently, such a hypothetical "portfolio" indicates the market efficiency`s benchmark.

Fig. 1: Capital Market Line Position

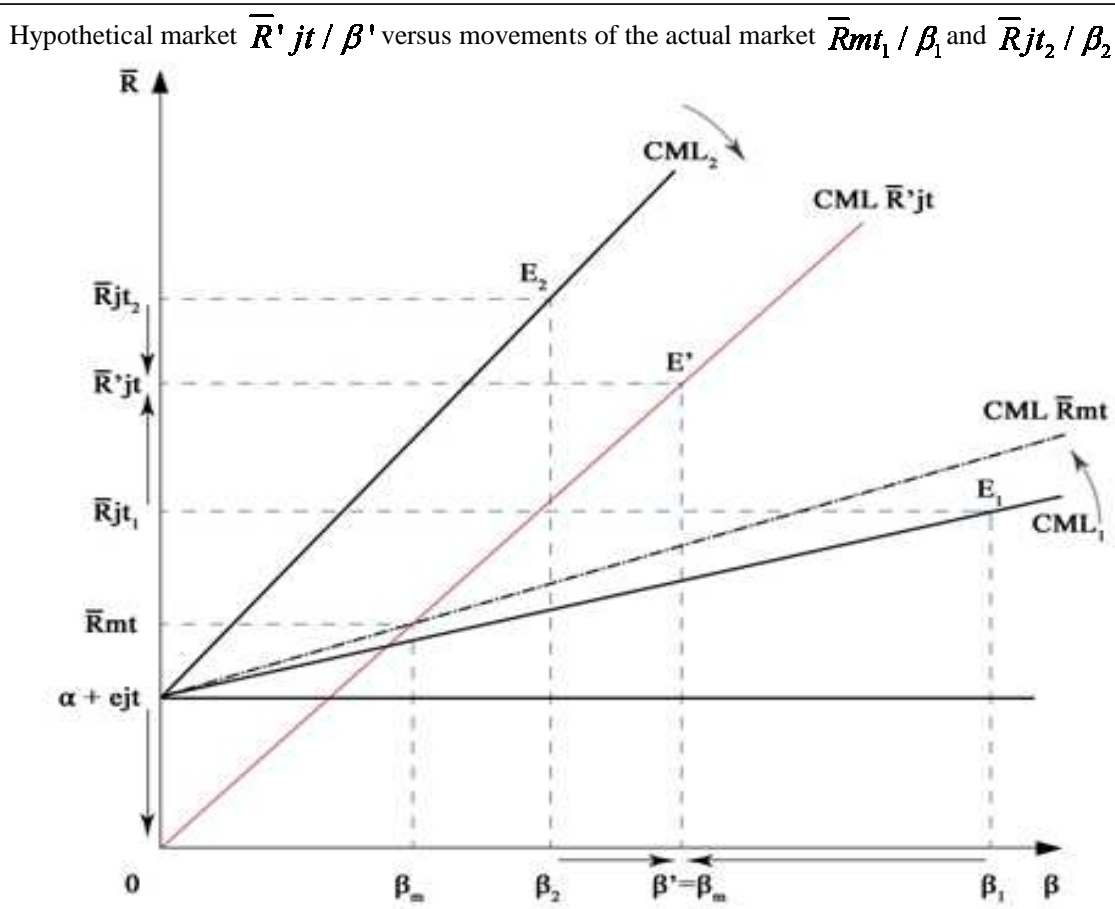

Legend:

$\overline{R_{j t 1}} / \mathrm{E}_{1} / \beta_{1} \ldots$. ex ante position actual market, where $\overline{R^{\prime}{ }_{j t}}>\overline{R_{j t}}$

$\overline{R_{j t 2}} / \mathrm{E}_{2} / \beta_{2} \ldots .$. ex ante position actual market, where $\overline{R^{\prime}{ }_{j t}}<\overline{R_{j t}}$

$\overline{R_{j t}} / \mathrm{E}^{\prime} / \beta^{\prime}$....... ex ante position actual market, for $\overline{R_{j t}}=\overline{R^{\prime}}$

$\overline{R_{m t}} / \mathrm{E} / \beta$........ initial equilibrium, actual capital market.

Shift of the LM schedule as a consequence of possible movements $R_{j t}^{\prime}$ towards the equilibrium $E^{\prime}$ caused by a fall of the information asymmetry.

Conversely, in the opposite case when the actual ex ante rate of return $\overline{R^{\prime}{ }_{j t 2}}$ were autonomously higher than the implicit efficiency equilibrium 
rate $\overline{R_{j t}}$, the process of rising market "efficiency", possibly complemented by increasing market "completeness" is causing a fall of the former actual return towards the latter intrinsic rate. This movement is combined with the corresponding decline in the volatility $\sigma_{j}^{\prime}$ of the actual market return towards the equilibrium mean-variance ratio level $\mathrm{E}=R_{j t} / \sigma_{j}$, generating a "cleansing" optimization of the market assets allocation along the declining information asymmetry. These convergences create macroeconomic effects then interpretable for example within the general framework of the IS-LM Hicksian model of the general equilibrium, holding certain other factors constant. At this point the "real and financial markets are simultaneously in balance at the equilibrium income and the rate of return"(Mach, 2001, p.65).

It is therefore possible to assume that for example given the money supply, level of income, price index, interest/exchange rate policy, ceteris paribus in the short term, the autonomous growth of the actual rate $\overline{R^{\prime}{ }_{j t 1}}$, towards the implicit "effective" rate $R_{j t}$, would cause the following effects, as a result of increasing market effectiveness (refer to Fig. 2).

Fig. 2: The Information Asymmetry Effect

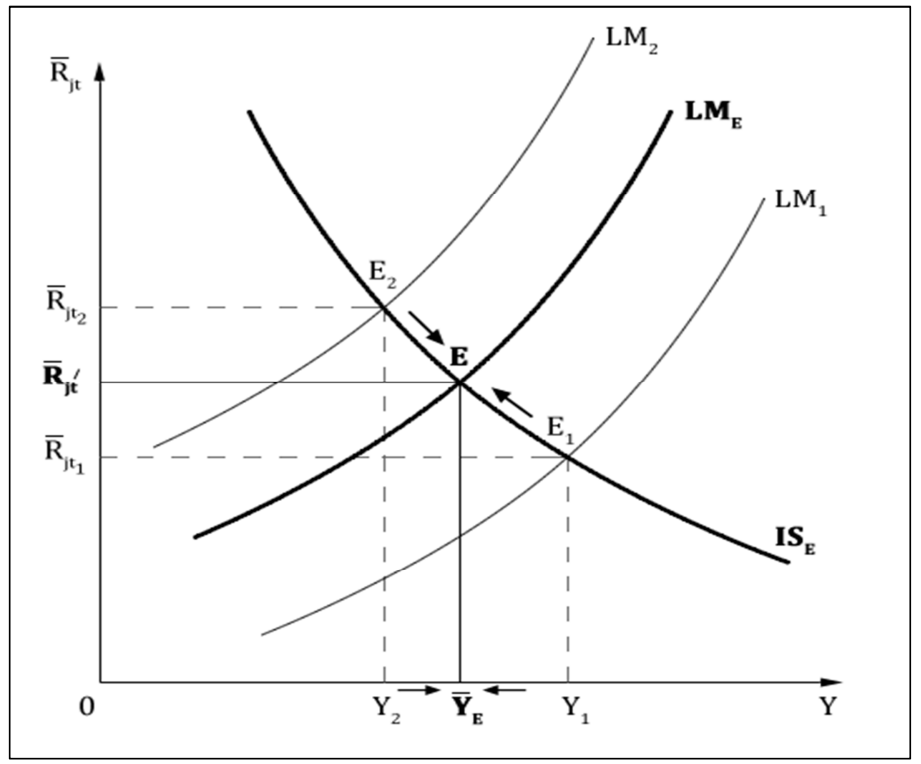

In the first case mentioned above, there is a probable vertical upward shift of the LM curve in the "north-west" direction along the IS schedule 
towards the equilibrium $\mathrm{E}$ featuring a simultaneous decline in the income Y. Assuming then a certain interest rate elasticity of the IS curve, the implicit equilibrium $\mathrm{E}$ is reached at a decline of $\mathrm{I}$ as a component of the aggregate demand. In such a situation it is possible to infer within the Keynesian framework a fall in the "speculative" demand for money ( $L s)$, as a result of the abovementioned escalation of the return $\overline{R^{\prime}{ }_{j t 1}}$. The income decline would of course also mean a fall of the transaction demand for money $(L t)$. Nevertheless, on the contrary there might be also a possibility of even a certain increase in the demand for idle balances $(L s)$ so long as the investors would like to maintain constant balance between increasing investment in equity/bonds and the cash component of their portfolio constant. According to for example Tobin,(1971,op.cit), it is possible to determine the elasticity of the LM schedule in this model as a function of the rate of return $r K=\bar{R} / q$, where $R$ represents the MEC rate of capital and $q$ the value of the capital stock, i.e. the degree of the capital investment as a speed at which investors desire to increase their holding of capital assets. The rate $r K$ is compatible with the equilibrium on the capital assets market and therefore it is then possible to apply it in the IS-LM framework. In this context it is necessary to point out that the original oversimplified Keynes' assumption stipulated only one type of the capital rate of return i.e. in the form of the interest rate on the long term bond with only an implied constant premium, to distinguish this rate from the rate of return on equity as oppose to the Tobin's extended framework. The rise in interest rates can also help to stimulate the Government debt with a possible fall in the velocity of money circulation (given the money supply M/P constant). On the other hand, from the point of view of the Friedmanian concept, the demand for speculative money can grow in the sense of investment demand related to the increasing expectations of returns on bonds $(r B)$ and equities $(r E)$ in the framework of the model concerned, not of course being offset by a possible decline in the permanent real income $P Y / R^{j 1}$ at a certain level of inflation $p$ in the period $t$, i. e. $M=f\left(P, r B, r E, p, P Y / \overline{R^{\prime}}\right)$.However, in the second, opposite case when the actual asset rate of return $\overline{R^{\prime}{ }_{j t 2}}$ were higher than the implicit equilibrium rate $R_{j t}$, and therefore falling towards this efficiency benchmark (refer to the Graph II), the macroeconomic process then involves a likely increase of the capital stock $q$, expansion of income $Y$ and a rise in the investment demand $I$ accompanied by e.g. an increase in the $L t$ and $L s$ demands for money in the Keynesian sense as well as a 
possible increase in the velocity of money circulation, given the $M s$ constant. On the other hand, the monetarist point of view would envisage a fall in the demand for investment funds due to a decline in the corresponding level of returns' expectations. In such a situation the LM schedule features a likely vector shift in the "south-east" direction along the IS schedule towards the equilibrium $E$, given the relevant ceteris paribus assumptions mentioned above. Obviously, if the basic Hicksian concept were expanded into the IS-LM-BP analytical framework, the intrinsic movement of the interest rate structure would undoubtedly also have the Balance of Payments ramifications involving the current and capital accounts' relationship to the exchange rate and the external equilibrium. The abovementioned process can also be demonstrated by movements of the corresponding Capital Market Lines, CML, where however the classical segment on the vertical axis featuring the "riskfree" component of the return, consistent with the framework of the Capital Asset Pricing Model (CAPM), was replaced by the return's component $\alpha$ mentioned above (refer to Fig. 1), consistent with the framework of the SIM.

\section{Generally, the application of the Single Index Model:}

$$
\overline{R_{j t}}=\alpha+\beta_{j} \overline{R_{m t}}+e_{j}
$$

where $\beta_{j}=\left(\frac{\sigma_{j}}{\sigma_{m}}\right) r_{j m}$,

therefore for the actual return

$$
\overline{R^{\prime}{ }_{j t}}=\alpha+\left(\frac{\sigma_{j}^{\prime}}{\sigma_{m}}\right) r_{m t} \overline{R_{m t}}+e_{j t}
$$

and for the pseudo-effective return

$$
R_{j t}=\left(\frac{\sigma_{j}}{\sigma_{m}}\right) \overline{R_{m t}},
$$

where $r_{j m}=1$ and $\left(\alpha, e_{j t}\right)=0$ 
Kuklik, R. G.: The Macroeconomic Effects of Information Asymmetry in the Capital Markets.

\section{Assuming:}

$R_{j t}>\overline{R^{\prime}{ }_{j t 1}}$ and therefore $\overline{R^{\prime}{ }_{j t 1}} \rightarrow R_{j t}$

$$
\begin{aligned}
& \text { then } \quad\left(\frac{\sigma_{j}}{\sigma_{m}}\right) \overline{R_{m t}}>\left(\frac{\sigma_{j}^{\prime}}{\sigma_{m}}\right) r_{j m} \cdot \overline{R_{m t}}+\left(\alpha+e_{j t}\right) \\
& \text { and } \quad \overline{R_{m t}}\left\{\frac{\sigma_{j}-\sigma_{j_{-}} r_{j m}}{\sigma_{m}}\right\}>\left(\alpha+e_{j t}\right)
\end{aligned}
$$

for $\left(\alpha+\mathrm{e}_{\mathrm{jt}}\right) \longrightarrow 0$ and $r_{j m} \longrightarrow 1, \sigma_{j}>\sigma^{\prime}{ }_{j}$ and $\sigma_{j} \longrightarrow \sigma_{j}$

where the equilibrium position at $\mathrm{E}^{\prime}$

$$
\begin{aligned}
& \left(\frac{\overline{R^{\prime}}}{\sigma_{j t}{ }^{\prime}}\right)=\left(\overline{\frac{R_{j t}}{\sigma_{j}}}\right) \\
& \left(\alpha+e_{j t}\right) \rightarrow 0
\end{aligned}
$$

is gradually reached due to the increasing market efficiency as the consequence of the falling information asymmetry.

\section{Assuming:}

$$
R_{j t}<\overline{R_{j t 2}} \text { and therefore } \overline{R_{j t 2}^{\prime}} \longrightarrow R_{j t}
$$

then conversely $\sigma_{j}<\sigma^{\prime}{ }_{j}$ and $\sigma_{j}^{\prime} \longrightarrow \sigma_{j}$

where the equilibrium $\mathrm{E}^{\prime}$

$$
\left(\frac{\overline{R^{\prime}}{ }_{j t}}{\sigma_{j}{ }^{\prime}}\right)=\left(\frac{\overline{R_{j t}}}{\sigma_{j}}\right)
$$

is reached again under the same conditions as under the assumption. 


\section{Conclusion}

Information is considered to be one of the fundamental factors in the process of creating new economic values under the circumstances of any model relating the price behavior of securities to the market as a whole and its effective proliferation is the subject of the Government policy measures. The concept of financial market regulation is based on an assumption that the capital markets are inclined to so called "market failure" which particularly manifests itself as the phenomenon of information asymmetry. "Effective functioning of the capital markets is conditioned upon the activities of fully informed participants. This is not the case of not regulated markets where different investors have also different, more or less complete price-determining information sets at their disposal" (Musílek, 2002, p. 107) thus experiencing this phenomenon. In a less "efficient" capital market the information asymmetry can cause distortions in allocation of economic resources which alter the optimal income return distribution as well as formation of capital flows and the market capitalization as a whole therefore affecting the economic growth. The main thrust of the concept of financial regulation is aiming towards securing the full, up to date and true information disclosure by the market participants concerning the traded financial instruments, the legal conduct of the financial activities of the firms and their adherence to the stipulated law, rules and regulations.

Using the analytical framework outlined in this article, it is possible to demonstrate that depending on the ex ante position of the actual market return versus the intrinsic "efficiency equilibrium", a rise in the market efficiency caused by a decline in the information asymmetry can create either stimulating or dampening effects on the demand for money as well as the aggregate demand, ceteris paribus. The key assumption of the SIM requires that "there are no effects beyond the market that account for comovement between securities" (Elton\&Gruber, 1981, p. 109). However, the market behavior is certainly much more complex and the "market efficiency" cannot be evaluated in a vacuum by only a simple set of fundamental laws, such as the utility theory, the principle of no arbitrage, random walk process, etc., from which a rigorous general theory with practical application could subsequently be developed. Again investors certainly cannot rely on the seemingly comforting message that all what is needed is to decide an acceptable return-risk ratio. Because of such a complexity of different factors affecting security prices, the concept of behavioral finance has grown to become an alternative approach trying to explain more clearly how investors individually as well as collectively appear to act. For example, the sacrosanct assumption of rationality has 
Kuklik, R. G.: The Macroeconomic Effects of Information Asymmetry in the Capital Markets.

been attacked: they are systemic deviations from rationality with consequences for macroeconomic behavior that need to be explored. Using the words of Joseph Stiglitz (2010, op. cit).), "changing paradigms is not easy. Too many have invested too much in the wrong models. Like the Ptolemaic attempts to preserve earth-centric views of the Universe, there will be heroic efforts to add complexities and refinements to the standard paradigm. The resulting models will be an improvement and policies based on them may do better, but they too likely to fail. Nothing less than a paradigm shift towards New Economic Thinking will do!"

Nevertheless, the role of the information content of security prices undoubtedly still lies at the heart of investors' decision making process no matter what other possible factors can influence it. A decline in the information asymmetry generated for example by more effective regulatory measures sharpens the investment return's expectations and is certainly enhancing the fairness of the "level playing field" for all market participants. It is therefore hoped that the general outline set out in this short article would lead to a further research to support this hypothesis.

\section{References}

[1] Dodd, P. (1980): Mergers, Proposals and Stockholders Wealth. Journal of Finance, 1980, vol. 8, no. 2, pp. 105-137.

[2] Elton, E. J. - Gruber, M. (1981): Modern Portfolio Theory and Investment Analysis. New York, Wiley, 1981.

[3] Gravelle, H. - Rees, R. (1992): Microeconomics. Boston, Addison Wesley, 1992.

[4] Mach, M. (2001): Makroekonomie. Praha, Melandrium, 2001.

[5] Mandelbrot, B. - Hudson, R. L. (2006): The (Mis) Behavior of the Markets. New York, Basic Books, 2006.

[6] Musílek, P. (2002): Trhy cenných papírů. Praha, Ekopress, 2002.

[7] Stiglitz, J. (2010): Needed: A New Economic Paradigm. [on-line], Financial Times, c2010, [cit. $12^{\text {th }}$ August, 2012],

<http://www.ft.com/intl/cms/s/0/d5108f90-abc2-11df-9f02-00144fea bdc0.html\#axzz1g4E6dcjM>.

[8] Tobin, J. (1971): Essays in Economics. Volume I: Macroeconomics. Chicago, Markham, 1971.

[9] Van Quang, T. (2007), Testing the Weak Form of Efficient Market Hypothesis for the Czech Stock Market, Politická Ekonomie, 2007, vol. 55 , no. 6 , pp. 751-772. 


\title{
The Macroeconomic Effects of Information Asymmetry in the Capital Markets
}

Robert G. KUKLIK

\begin{abstract}
It is possible to say that no matter how the Efficient Market Hypothesis has been criticized and/or overhauled, a degree of the relevant data proliferation is crucial to the investor's decision making process. The information asymmetry is then a phenomenon which creates distortions in a performance of the capital market. The "pseudoeffective" market model is attempting to highlight the impact of this phenomenon on some macroeconomic variables conducive to the general economic equilibrium.

Key words: Information asymmetry; "Pseudoeffective" market model; Actual return; "Effective" market equilibrium; IS-LM framework.
\end{abstract}

JEL classification: G14. 